Puryear - Bruers - Erdős (2017): On a failed defense of factory farming. J Agric Environ Ethics (2017) 30:311-323.

DOI 10.1007/s10806-017-9666-7

\title{
On a Failed Defense of Factory Farming
}

\author{
Stephen Puryear \\ smpuryear@ncsu.edu \\ Department of Philosophy and Religious Studies, North Carolina State University \\ Raleigh, NC, USA \\ Stijn Bruers \\ stijn.bruers@gmail.com \\ Department of Philosophy and Moral Science, Ghent University, Ghent, Belgium \\ László Erdős \\ erdos.laszlo@okologia.mta.hu \\ MTA Centre for Ecological Research, Institute of Ecology and Botany, Vácrátót, \\ Hungary
}

Abstract Timothy Hsiao attempts to defend industrial animal farming by arguing that it is not
inherently cruel. We raise three main objections to his defense. First, his argument rests on a
misunderstanding of the nature of cruelty. Second, his conclusion, though technically true, is so
weak as to be of virtually no moral significance or interest. Third, his contention that animals
lack moral standing, and thus that mistreating them is wrong only insofar as it makes one more
disposed to mistreat other humans, is untenable on both philosophical and biological grounds.

Keywords Factory farming · Animals · Cruelty · Sentience - Rationality · Vegetarianism

In a recent contribution to this journal, Timothy Hsiao (2017) defends industrial livestock production (hereafter "factory farming") against the charge that it is cruel toward animals. He does so by arguing that this type of farming is not inherently cruel. On his view, "an act is cruel if it reveals a corrupt character or if it corrupts one's character so as to make one more disposed to mistreating humans" (p. 49). But many people, he claims, are able to carry out the various tasks involved in this industry-confining, castrating, slaughtering, etc.-without being corrupted in the relevant way, and since (on his view) animals lack moral standing, performing such tasks need not reveal an already corrupt character. Hence, even though these practices might be cruel in some cases-namely, when they are carried out by people who are prone to being corrupted by them-they are not universally or inherently cruel.

On our view, both this argument and the general perspective on animals that it exemplifies are deeply flawed. In the first place, the argument rests on a misunderstanding of the nature of cruelty. Second, the argument's conclusion, though strictly speaking true, is so weak as to be almost entirely without moral significance or interest. Finally, Hsiao's contention that animals lack moral standing, and thus that mistreating them is wrong only because it makes 
humans more disposed to mistreat one another, is untenable on both philosophical and biological grounds. We argue for each of these points in what follows. ${ }^{1}$

\section{The Nature of Cruelty}

Hsiao characterizes the definition quoted above as his "formal definition" of cruelty (p. 49). Paraphrasing slightly, it says that an act is cruel if (and only if) it either (i) corrupts one's character in such a way as to make one more disposed to mistreat humans, or (ii) reveals an already corrupt character. We have taken the liberty of adding the parenthetical "and only if" because this is needed in order for the argument to go through: it follows that factory farming is not (inherently) cruel only if this definition states a necessary and not merely a sufficient condition for cruelty, since otherwise cruelty might also take some other form which is inherently present in factory farming.

Ironically, this definition, taken at face value, seems to imply that factory farming is cruel. Even if we grant Hsiao's point that some people are able to perform the tasks involved in industrial livestock production without becoming more disposed to mistreat other humans, their willingness to perform these tasks in the absence of a sufficient moral justification for doing so seems to reveal a corrupt character, and thus to satisfy condition (ii) of the definition. Simply put, to cause a sentient being to suffer unnecessarily, that is, without a sufficient moral justification, reflects a corrupt character. But there is no sufficient moral justification for the suffering caused by factory farming, at least under present circumstances, since all of our nutritional needs can in general be met without meat or other animal products (Craig \& Mangels 2009). Hence, even by Hsiao's own definition, we ought to conclude that factory farming is cruel.

As far as we can tell, Hsiao does not draw this conclusion because on his view, causing a being who lacks moral standing to suffer, even unnecessarily, corrupts one's character, or reveals a corrupt character, only if one happens to be susceptible to such corruption. He writes:

Since animals lack moral status, what counts as a cruel practice towards animals will be person-specific. A practice that evinces a cruel character for one person may not be considered cruel for another. John Smith may be able to work in a slaughterhouse for his entire life without there being anything amiss about his character. (p. 49) However, this thesis - that the cruelty of causing animals to suffer depends on the susceptibility of one's character to corruption-has some rather counterintuitive implications. Suppose John Johnson, who works at a Christmas tree farm, believes that trees are fully sentient. Yet every year he cuts down many of these trees, believing that he is causing them to suffer and that this suffering is being inflicted for a relatively frivolous cultural reason. He justifies this in his own mind by noting that he needs the paycheck and that this is, after all, what's done. Now it seems entirely plausible to suppose that in causing beings which he believes to be sentient to suffer without a sufficient justification, Johnson is corrupting his character, making himself more disposed to mistreat other sentient beings, specifically humans. But surely it is implausible to think that cutting these trees down is actually cruel. Or consider Tom Thompson, a latter-day Cartesian who believes that animals are mere machines, and thinks nothing of beating a stray dog with a baseball bat for his amusement. Since on his view dogs are mere things and thus

\footnotetext{
${ }^{1}$ For earlier statements of his view, see Hsiao (2015a, b); for criticisms of these earlier papers, see Erdős (2015), Bruers (2015), and Puryear (2016).
} 
incapable of suffering, beating the dog with a bat is in all essentials no different from hitting a piñata at a child's party. Arguably, beating the dog has no effect on Tom's character, any more than hitting a piñata. Yet no reasonable person would suppose that beating the dog for one's amusement is not cruel. Alternatively, we may suppose that Thompson has an unusual psychology which allows him to abuse sentient animals without corrupting his character.

Perhaps he has such a firm grasp on the sharp difference between animals and humans that his mistreatment of the former never leads to mistreatment of the latter. Even so, it would be preposterous to suppose that abusing the dog for amusement is not cruel. Cruelty just isn't a function of character in the way that Hsiao suggests.

Returning to Hsiao's definition of cruelty, its most obvious flaw is that it is too inclusive. Assume for the sake of argument that it is possible for one's character to be corrupted. Given this assumption, there would seem to be many examples of actions that satisfy this definitionthat either have a corrupting tendency, or else evince a corrupt character-yet involve no cruelty at all. One such example was the unusual case of John Johnson discussed in the previous paragraph. But there are many more mundane examples. Suppose one chooses to take a bribe, or embezzle small amounts of money from a wealthy employer, or listen to music that glorifies violence, or indulge in highly addictive drugs. Arguably, any one of these actions might well have a corrupting influence on the one who performs them, and in particular, might well make them more apt to mistreat other humans. The one who takes a bribe, or who embezzles, might through these actions become desensitized to breaking rules or stealing in ways that would harm others. Listening to violent music might desensitize one toward violence and make one more likely to be violent toward others. Becoming addicted to drugs might lead one to be more callous toward others, and thus more inclined to mistreat them. All of these actions would seem to have the relevant kind of corrupting tendency on a wide range of people. Furthermore, at least some of these actions would seem to evince a corrupt character. Yet none of them seem to involve any cruelty, even in cases where they corrupt. Whatever we might think about taking addictive drugs or listening to violent music, these activities are not cruel. And even though stealing from one's employer or taking a bribe might be immoral, such actions are not typically cruel, even if they do typically have a corrupting influence.

The fundamental problem with Hsiao's definition is that it fails to capture an essential feature of cruelty, namely, that of having an improper regard for the badness of the suffering that one causes another. We can make this more precise by availing ourselves of a distinction that Regan (1980: 533-534) helpfully draws between two kinds of cruelty (cf. Tanner 2015: 823). The first occurs when one causes another to suffer for the sake of the suffering itself. In such cases, the suffering of the other is not (or not merely) the means to some further end; rather it is the end, and accordingly one takes delight in that suffering. The second kind of cruelty occurs when one causes great suffering in another not for its own sake, but nonetheless with callous indifference to the badness of that suffering. Following Regan, let us call cruelty in the first of these senses sadistic cruelty, and in the second brutal cruelty. And let us take an action to be cruel simpliciter just in case it is cruel in either the sadistic or the brutal sense.

We can now see why acts like those given as examples above_taking a bribe, stealing from one's employer, listening to violent music, taking addictive drugs-are not in fact cruel. For even if they cause others to suffer, that is not usually the intent, and even if the one who performs these actions is indifferent to the suffering they cause others, that suffering is usually 
not great enough to make the case an instance of brutality. So these actions are typically neither sadistic nor brutal. Yet some of them do typically reveal a corrupt character, and all of them seem to make the agent more disposed to mistreat other humans: they all satisfy Hsiao's "formal definition" of cruelty. Hence, that definition is wrong.

This brings us to a second irony in Hsiao's discussion. In another recent essay (Hsaio 2015a: 289), he describes cruelty in rather different terms: "Cruelty, whatever else it may be, consists of practices that inflict needless or excessive suffering (i.e. suffering beyond what is required) or suffering for its own sake." In the terminology we have adopted here, to cause needless or excessive suffering is brutal, at least if that suffering is great; to cause suffering for its own sake is sadistic. So this earlier definition of cruelty corresponds roughly to the one we have proposed here. On such a conception, however, factory farming does turn out to be cruel, since the suffering it inflicts on animals goes beyond what is required for human flourishing (cf. Puryear 2016: 700-701). We believe Hsiao would have done better to stick with this earlier conception and admit that factory farming is cruel. His shift to an agent-corruption definition of cruelty is a step in the wrong direction.

\section{Hsiao's Conclusion: True, but Insignificant}

As a result of his misconception of cruelty, Hsiao's argument proceeds along impertinent lines. If he wants to establish that factory farming is not inherently cruel, then whether it inherently evinces or causes a corrupt character is beside the point. What he needs to argue is that factory farming is not inherently either sadistic or brutal. Now as it happens, we believe that a cogent argument can be made for this conclusion. Briefly, the argument is this. It is not inherent to factory farming that workers cause the animals to suffer for the sake of the suffering itself, as Hsiao himself correctly notes (p. 51). Though some workers may well take delight in the suffering they cause, this is certainly not a necessary or inherent feature of factory farming. Hence, factory farming is not inherently sadistic. Further, even though the workers often cause great suffering, it is not inherent to factory farming that they be indifferent to that suffering. To see why, just imagine a scenario in which factory farming of animals is the only way to provide adequate nutrition for the survival of humans. In such a scenario, treating animals in these ways need not betray an indifference to their suffering. Indeed, we may suppose that the workers in this scenario feel bad about the suffering they cause, but cause it nonetheless because they believe (perhaps correctly) that it is necessary for human survival and is thus morally justified. Under such circumstances, factory farming would not be brutal either. And so factory farming is not inherently cruel: it is neither inherently sadistic nor inherently brutal. Despite the flaws in his argument, then, Hsiao's conclusion is true in the final analysis.

The point we want to emphasize here is that this conclusion, though true, is so weak as to be of little significance or interest. In the first place, an action's being inherently cruel does not prevent it from being typically or even almost always cruel. Nor does it prevent it from being cruel under the circumstances in which it actually happens to occur. Tightening the vise on my workbench is not inherently cruel. But if someone's hand is in that vise, and I delight in, or am indifferent to the suffering that tightening it would cause, then tightening it suddenly becomes an instance of cruelty. Similarly, factory farming of animals is not inherently cruel. But if, as in present circumstances, it is practiced when doing so is not necessary for human survival or flourishing, when our nutritional and other needs can be met without subjecting animals to such 
considerable suffering, then it necessarily betrays an indifference to that suffering, and is thus brutal. In the circumstances in which it actually takes place, then, factory farming is cruel.

In the second place, even if factory farming were not cruel under present circumstances, it would not follow that it is not morally objectionable or even reprehensible. Being cruel is one way for an action to be morally wrong, but it is not the only way. For example, painlessly taking the life of an innocent moral agent need not be cruel, because it need not cause any suffering, but it may yet be morally wrong. Alternatively, an action (e.g., stealing from someone) may be morally wrong, yet not cause the person to suffer greatly enough to qualify as brutal, and thus not be cruel. Similarly, factory farming could fall short of being cruel, and yet still be morally objectionable. Indeed, most if not all moral arguments against factory farming, including the "basic argument" that Hsiao offers as an exemplar (p. 39), do not invoke the concept of cruelty at all, but merely purport to show that factory farming is morally wrong. Hsiao's narrow focus on cruelty leaves these arguments largely untouched.

Thus, even though Hsiao's conclusion is technically true, it is almost entirely inconsequential. Even if factory farming is not inherently cruel, it is still cruel in the present circumstances. And even if it weren't cruel, it would not follow that it is not morally objectionable. Hsiao's argument therefore has little significance for the debate about the ethics of factory farming.

\section{The Moral Status of Animals}

Hsiao devotes much of his paper to arguing that animals lack moral standing, that is, "that animal suffering is not morally salient, and that animals lack the required features necessary for membership in the moral community" (p. 38). On his view, only beings with a rational nature, or a capacity to reason, have moral standing. But animals lack such a nature and capacity. So animals lack moral standing. This thesis then serves as the "metaphysical foundation" of Hsiao's claim that factory farming is not inherently cruel. "Since animals lack moral status," he claims, "what counts as a cruel practice towards animals will be person-specific" (p. 49). This is because, on his view, only human suffering is morally salient, and so treating animals in a certain way can be cruel only insofar as it leads to an increase in human suffering. We think this view suffers from several major shortcomings.

\section{Sentience vs. Rationality}

To begin with, Hsiao stacks the deck in favor of his rationality criterion for moral standing. He claims that the whole point of morality is to be moral, and then baldly asserts without any argument that being moral consists in knowing what is good for oneself and freely acting on the basis of that knowledge. The knowledge he has in mind is the sort of abstract cognition required for "Understanding, articulating, and fulfilling the demands of morality" (p. 45), which animals lack. Hence, since morality is essentially a matter of pursuing what is good for those with the capacity for this kind of abstract knowledge, it follows that only such beings, i.e., rational beings, have moral standing; only their suffering is morally salient in itself. But why should we go along with this eudaimonistic assumption that morality is about pursuing what is good specifically for oneself, particularly when viable alternatives are also in play? Many philosophers today think that being moral consists in something like pursuing the general happiness, where happiness is cashed out in terms of pleasure and the absence of suffering - of oneself, but also of others. 
Others conceive of being moral as a matter of having certain other-regarding sentimentsempathy, sympathy, compassion, or the like-which move the agent to lessen the suffering of others. We grant that if morality is exclusively about abstractly conceiving and freely pursuing one's own good, then only those who are capable of this kind of knowledge will have moral standing. But if morality is about advancing the happiness or well-being of all sentient beings, or all other sentient beings, then moral standing will belong not just to those who are capable of being moral, but to all those who are capable of suffering —not just to moral agents, but to moral patients as well. Further, if being moral is a matter of having certain other-regarding sentiments, such as empathy, then it may well be that many animals are capable of being moral, and thus of being moral agents. ${ }^{2}$ Hence, whether animals belong to the moral community depends crucially on our conception of morality, and given the existence of viable alternatives, it is illegitimate for Hsiao simply to assume an anthropocentric, eudaimonistic framework in his defense of factory farming.

In a way, we agree that the moral community consists of those who know and pursue their own good. But the relevant kind of knowledge, on our view, is not abstract knowledge of one's "purpose" (assuming there is such a thing), but direct knowledge, or knowledge by acquaintance, of what is subjectively good for oneself, that is, what one desires. Unlike abstract knowledge of one's purpose, about which it seems one might easily be wrong, direct knowledge of this sort is immune to doubt. When one feels agony, one can be certain that one feels agony and that one does not want this feeling. Moreover, this is a kind of knowledge that can reasonably be ascribed to most animals. A dairy cow, for example, can be said to know that it is good to eat when hungry, and bad to be without her newborn calf. Likewise, at least most animals also pursue what is subjectively good for themselves, just as the cow pursues food, avoids pain, and so forth. On our view, then, it is quite true, in a sense, that membership in the moral community belongs to all and only those beings who know and pursue their own good. But the knowledge and pursuit here is that characteristic of sentience, not rationality.

We have already offered one consideration that supports this view. If rationality were the criterion for moral standing, then cruelty toward animals would be at worst only instrumentally morally wrong. But, intuitively, it is morally wrong to be cruel to animals even apart from any effects it might have on oneself or other humans. If a person stranded and alone on a desert island decided to torture some wild boars for fun, and happened to have a character that would be unaffected by this, his actions would still be cruel. What matters here, as we have noted, is that the animals are being caused to suffer for the sake of the suffering itself, not that the person's character is being corrupted, or that some human is indirectly being harmed. Animal suffering is therefore morally salient, and sentience, not rationality, is the correct criterion for moral standing.

In opposition to this view, Hsiao objects that proponents of a sentience criterion cannot explain why the harms we cause animals are moral harms, as when we harm fellow humans, rather than non-moral harms, as when we harm a plant by depriving it of water or sunlight, an internal combustion engine by depriving it of oil, or a computer by exposing it to a virus (p. 41). Why should we think that the welfare of an animal matters morally, he asks, when the welfare of plants and machines does not? But we believe there is a simple and convincing reply to this

\footnotetext{
${ }^{2}$ On the moral lives of animals, see Bekoff \& Pierce (2009) and Rowlands (2012). On the ability of pigs and chickens in particular to feel empathy, see, respectively, Marino \& Colvin (2015) and Marino (2017).
} 
objection. Briefly put, nearly everyone agrees that we harm humans in a moral sense when we starve them, confine them, cause them unjustified pain, and so forth, even when these humans are too young to reason about these experiences. But the harms we cause animals when we starve them, confine them, cause them unjustified pain, and so forth, are of the same fundamental nature as these harms inflicted on humans. The "harms" we cause to machines, which are really just damages, are not at all like the moral harms we inflict on humans. When we starve a human, we cause that person to suffer, to have an unpleasant, negative experience. When we deprive an engine of oil or expose a computer to a virus, those machines cease to function well. But we do not cause them to suffer. Similarly, when we harm a plant, there is, as far as we can tell, no suffering, no negative experience. In the case of animals, however, the situation appears to be exactly similar in all relevant respects to the human case. Starving an animal, at least if that animal has a relatively complex nervous system, is fundamentally the same kind of thing as starving a human. To be sure, many humans have a more complex kind of suffering when they are starved, because in addition to the bodily suffering, they experience various forms of mental anguish. But young humans do not experience these more complex forms of suffering, and so starving them produces essentially the same kind of experience as starving an animal. Given this fact, it would be highly arbitrary to suppose that the harms caused to animals are non-moral, while the harms caused to humans, even small children, are moral. The proponent of the sentience view is simply treating like things alike. It is the anthropocentrists, such as Hsiao, who are drawing a distinction without a (relevant) difference.

\section{Marginal Cases and Root Capacities}

Besides its inability to support a plausible view of animal cruelty and its arbitrary differentiation between human and animal suffering, Hsiao's anthropocentric conception of morality runs aground on the shoals of the problem of marginal cases. In brief, the problem is that Hsiao wants all (and only) humans to have moral standing. But he grounds moral standing in the capacity for rationality. Hence all humans must have a capacity for rationality. Yet this is apparently not the case, insofar as both young humans and humans with serious mental disabilities lack the ability to reason. The challenge, then, is to explain how these "marginal cases" can have moral standing, without being forced to acknowledge that animals have moral standing too. At this point, Hsiao introduces the notion of a root capacity. He posits that all humans, even those who lack an "immediate" capacity to reason, nonetheless have a root capacity for reason and thus have a rational nature. All humans thus have moral standing, even though in some sense some of them may be unable to have the kind of abstract knowledge required for being moral.

The first and most obvious problem with this move is its transparently ad hoc character. That is, Hsiao seems to posit these mysterious root capacities solely for the purpose of achieving the desired result-namely, that of extending moral standing to those humans who can't actually reason, without extending it to animals who are more-or-less equally rational. Hsiao began by saying that morality is about being moral, which involves having a kind of abstract knowledge and the ability to act on that knowledge. In the face of humans who lack the ability for this kind of knowledge, however, he does not bite the bullet and admit that these humans, being unable (or not yet able) to be moral, lack moral standing. Rather, he moves the 
goalposts; whereas before he had said that morality is about being moral, he now says, in effect, that morality is about having the capacity for being moral. And in order to explain how an infant or someone born with a severe brain defect can have such an advanced capacity, he conveniently, and apparently for this purpose alone, posits a root capacity in every human organism.

To be sure, Hsiao does offer several independent reasons for positing root capacities. But they are all dubious. For instance, he claims that there is an "inherent normativity" in living organisms that cannot be explained apart from root capacities (p. 47). On his view, humans don't just see; they ought to see, and this is no less true of humans who can't actually see. Similarly, all humans ought to be rational, even if they aren't actually rational, say, because of a congenital brain defect. But this is suspect. For one thing, Hsiao seems to be deriving a normative claim such as 'person $X$ ought to have $Y$ ' from a factual claim such as 'person $X$ has property $Y$ ', which is generally invalid. Why should the fact that most humans are rational entail that all human organisms ought to be rational? For another, why should we think that a person ought to see, if for example they lack eyes due to some genetic mutation? Presumably Hsiao would say that a human ought not to have such a genetic mutation, but it is rather mysterious what makes this the case. If a human fails to develop an ability to see or reason, for whatever reason, who's to say that the human should have been otherwise? Relatedly, how can we rule out the possibility that farm animals ought to have been rational? It will be said that cows, pigs, and chickens do not display an ability for advanced, abstract cognition. But might we not say with equal plausibility that, for instance, all humans ought to be sinless, even though they all fall far short of that goal? If it can be true that humans ought to be sinless, and thus that they have a root capacity for sinlessness, even though humans fall well short of that mark, then could it not also be the case that animals ought to be rational, and thus that they have a root capacity for rationality, even though (or if) they fall well short of that level of cognition?

Relatedly, Hsiao claims that we need root capacities in order to explain why there is something bad or defective about lacking normal human capacities such as those for sight or rationality (pp. 47-48). But we disagree. To say that being blind or being unable to reason is bad or a defect is to say two things: (1) humans commonly develop the relevant capacity (to see, to reason), and (2) those capacities are conducive to desire-satisfaction, or more fundamentally, increase the individual's fitness (i.e., are beneficial for survival and reproduction). So we consider blindness to be bad or a defect in humans because humans commonly have sight, and having sight aids humans in satisfying their desires, or more fundamentally, in surviving and reproducing. The same holds for rationality. There is no need to posit root capacities in order to explain why the lack of such abilities is bad or defective.

Hsiao also maintains that root capacities explain why organisms develop as they do: "Root capacities are what dictate the growth, development, and proper functioning of an individual .... Human embryos, for instance, develop in the way they do because their growth is teleologically directed from within by their nature. An embryo's root capacities function as a blueprint that dictates how the process of biological development should proceed" (p. 47). And again: "the root capacity to see is what explains why humans develop eyes to begin with. The very reason why human development proceeds in lawlike ways is because of root capacities that direct the process of human life. Without appeal to these capacities, human development becomes completely inexplicable" (p. 48). But these claims are biologically dubious. Hsiao is 
assigning to root capacities a role that is in fact played by certain biochemical and biological mechanisms, which are mostly well-known. Human embryos develop the way they do because of genes and other, related mechanisms. It is these mechanisms that explain why we develop eyes, and humans have these mechanisms solely because they have been selected for by evolution-they conferred a survival advantage. Likewise, to the extent that there is a blueprint that dictates how biological development should proceed, this blueprint consists in our genes and in other biochemical and biological mechanisms, not some mysterious root capacities. Finally, the fact that organisms develop in lawlike ways is also determined by various biochemical compounds and pathways. There is no need to posit root capacities to explain these biological facts. So Hsiao's appeal to root capacities does indeed appear to be entirely ad hoc.

Beyond this, there is the further problem that Hsiao's appeal to root capacities involves, assumes, or commits him to several biologically suspect views. First and foremost, it involves a traditional form of species-essentialism that the overwhelming majority of biologists and philosophers of biology regard as having been decisively refuted by modern evolutionary biology. Indeed, many regard the kind of essentialism Hsiao advocates as having no greater scientific legitimacy than alchemy or astrology, as no more compatible with evolution than geocentrism is with modern astronomy. Now, to be sure, a few philosophers have recently challenged this orthodoxy, as Hsiao points out (see, e.g., Oderberg 2007). We will not undertake to evaluate their arguments here; that would take us too far afield. Our point is simply that Hsiao's defense of factory farming hinges on a commitment to traditional biological essences that is widely rejected by the relevant experts. In order for that defense to succeed, the burden of proof falls on him to show that biological essentialism is not so problematic after all.

Second, Hsiao's claim that all and only humans have a rational nature, in virtue of which they belong to the moral community, appears to presuppose that taxonomic categories such as human, or more precisely, the genus Homo, are objectively real. But this seems highly doubtful. There is good reason to believe that taxonomic categories are nothing more than mental constructions introduced by us for the purpose of conveniently describing the world. One indication of this is that the life forms we see today have all evolved by gradual, almost continuous transitions, and thus do not fall into naturally distinct groups. As Ridley (2004: 5253) puts it, "[t]he idea that nature comes in discrete groups, with no variation between, is a naive perception. If the full range of natural forms, in time and space, is studied, all the apparent boundaries become fluid." On our view, the fact that these apparent boundaries are blurred points to the subjective nature of taxonomic categories. In this respect biological taxa are like time zones, which do not exist in nature, but are artificial constructs. Of course it is true that time zones capture something real. Nobody denies that the sun rises and sets at different times at different longitudes. But this does not mean that time zones as such are real (much less that each of them has an essence). There is a continuous variation upon which we impose our discrete categories. Time zones are constructs of our brains superimposed on a continuous variation in nature. ${ }^{3}$

\footnotetext{
${ }^{3}$ Compare Darwin (1859: 53-54): "I look at the term species, as one arbitrarily given for the sake of convenience to a set of individuals closely resembling each other, and that it does not essentially differ
} 
One could argue that continuous variation is not always the case among individual organisms, as we can recognize distinct classes of living beings at least in some cases. But it should be kept in mind that what we see today is only a snapshot, a kind of a cross-section, of evolution. We do not see the intermediate forms because they are extinct. Darwin $(1859,1871)$ himself stresses that evolution has to be gradual, and specific characteristics evolve in small steps. Of course, the rate of evolution can vary greatly, and some rather large jumps for single traits cannot be considered impossible. However, the overnight emergence of new taxa with a number of new characteristics is highly unlikely, and for genera, it can be ruled out completely. The set of features we see as human today (and which would probably be called "human nature" by Hsiao) appeared at different times during the evolution of our ancestors. As Darwin (1871: 226) notes, "In a series of forms graduating insensibly from some ape-like creature to man as he now exists, it would be impossible to fix on any definite point where the term 'man' ought to be used." In the light of evolution, taxa seem quite similar to time zones: they reflect an attempt to describe nature, but they do not exist in reality. ${ }^{4}$

Finally, Hsiao's view presupposes that the biological organisms in possession of what he calls a rational nature happen to be precisely those which belong to a certain taxonomic category. In other words, he assumes that essences and taxa coincide, and in particular that the capacity to reason correlates with membership in the genus Homo. But this is at least doubtful. For one thing, it would be rather difficult to show that no animals except humans can reason in the sense required for being moral. We know a great deal about animals, including a good bit about what they probably feel, but how and what they think is as yet mostly inaccessible for us. De Waal (1996) wondered whether extraterrestrial scientists studying human behavior would be able to recognize that humans do have the capacity to reason in moral matters. And if so, would they not conclude that chimpanzees also have this capacity? We know for sure that dolphins and other cetaceans are highly intelligent animals, but they are so different from us that we may not be in a position to make precise judgments about their level of rationality. Furthermore, we are simply not yet in a position to say whether all members of our genus, including our extinct relatives such as Homo erectus or $\mathrm{H}$. habilis, possessed the level of rationality necessary for moral reasoning. Perhaps some of them were able to distinguish between morally good and bad acts; others may have lacked this ability. Indeed it is entirely possible that clearcut members of Homo arrived on the scene before any individuals developed the capacity for such reasoning. Conversely, the capacity for moral reasoning may well have appeared before any individuals who were clearly human. For Hsiao to be right that all and only humans have a rational nature, it seems that the appearance of rationality would have to have coincided precisely with the appearance of humans, members of Homo, which would be nothing short of a miracle.

In summary, Hsiao's appeal to root capacities or essences in response to the problem of marginal cases is highly implausible. These capacities are mysterious and ad hoc; from an evolutionary standpoint, such biological essences are fictions; taxa (such as genus Homo) do

from the term variety, which is given to less distinct and more fluctuating forms. The term variety, again, in comparison with mere individual differences, is also applied arbitrarily, and for mere convenience sake."

${ }^{4}$ For detailed accounts of the mechanisms of evolution, see Ridley (2004), Futuyama (2013), and Barton et al. (2007). A short but accurate summary of evolution, accompanied by a discussion of its ethical implications, can be found in Rachels (1999). 
not exist in nature; and even if both essences and taxa were real, their coexistence would be highly improbable.

\section{Conclusion}

Hsiao attempts to defend factory farming by arguing that it is not inherently cruel. His conclusion is true, but insignificant. For factory farming is still cruel under the circumstances in which it presently takes place. Since our nutritional needs can generally be met apart from meat and animal products, subjecting animals to such treatment is not morally justified and thus requires a callous indifference toward the great suffering inflicted on them by this industry. But that makes factory farming cruel in the brutal sense of the term. Furthermore, even apart from considerations of cruelty, factory farming is morally wrong at least under the current circumstances. The suffering of animals is in all relevant respects like the suffering of humans, particularly young humans, and since the latter is morally salient, it stands to reason that the former is too. Thus, insofar as factory farming causes animals to suffer without a sufficient moral justification, this kind of farming is morally wrong.

Hsiao attempts to avoid this conclusion by arguing that only rational beings have moral standing. However, he does so by assuming, without any real argument, a controversial, anthropocentric conception of morality, thus stacking the deck in favor of his conclusion. Moreover, he fails to offer a plausible response to the problem of marginal cases. In particular, his appeal to root capacities is unacceptably ad hoc and saddles him with a number of biologically dubious assumptions. In the end, then, we believe Hsiao would do well to abandon this anthropocentric approach to morality and instead to embrace the more plausible view that the suffering of all sentient beings matters morally and thus that the unnecessary suffering caused by factory farming makes it immoral and even cruel.

\section{References}

Barton, N. H., Briggs, D. E. G., Eisen, J. A., Goldstein D. B., \& Patel, N. H. (2007). Evolution. Cold Spring Harbor: CSHL Press.

Bekoff, M., \& Pierce, J. (2009). Wild justice: The moral lives of animals. Chicago: University of Chicago Press.

Bruers, S. (2015). In defense of eating vegan. Journal of Agricultural and Environmental Ethics, 28(4), 705-717.

Craig, W., \& Mangels, A. (2009). Position of the American Dietetic Association: Vegetarian diets. Journal of the American Dietetic Association, 109(7), 1266-1282.

Darwin, C. (1859). On the origin of species. London: John Murray.

Darwin, C. (1871). The descent of man, and selection in relation to sex. London: John Murray.

de Waal, F. B. M. (1996). Good natured: The origins of right and wrong in humans and other animals. Cambridge: Harvard University Press.

Erdős, L. (2015). Veganism versus meat-eating, and the myth of "root capacity": A response to Hsiao. Journal of Agricultural and Environmental Ethics, 28(6), 1139-1144.

Futuyama, D. J. (2013). Evolution (3rd ed.). Sunderland, MA: Sinauer Associates. 
Hsiao, T. (2015a). In defense of eating meat. Journal of Agricultural and Environmental Ethics, 28(2), 277-291.

Hsiao, T. (2015b). A carnivorous rejoinder to Bruers and Erdős. Journal of Agricultural and Environmental Ethics, 28(6), 1127-1238.

Hsiao, T. (2017). Industrial farming is not cruel to animals. Journal of Agricultural and Environmental Ethics, 30(1), 37-54.

Marino, L. (2017). Thinking chickens: a review of cognition, emotion, and behavior in the domestic chicken. Animal Cognition, 20(2), 127-147.

Marino, L., \& Colvin, C. (2015). Thinking pigs: A comparative review of cognition, emotion, and personality in Sus domesticus. International Journal of Comparative Psychology, 28.

Oderberg, D. S. (2007). Real essentialism. New York: Routledge.

Puryear, S. (2016). Sentience, rationality, and moral status: A further reply to Hsiao. Journal of Agricultural and Environmental Ethics, 29(4), 697-704.

Rachels, J. (1999). Created from animals: The moral implications of darwinism. New York: Oxford University Press.

Rowlands, M. (2012). Can animals be moral? New York: Oxford University Press.

Regan, T. (1980). Cruelty, kindness, and unnecessary suffering. Philosophy, 55(214), 532-541. Ridley, M. (2004). Evolution (3rd ed.). Oxford: Blackwell.

Tanner, J. (2015). Clarifying the concept of cruelty: What makes cruelty to animals cruel. The Heythrop Journal, 56(5), 818-835. 